\title{
A Review of Parental Input, Investment and Social Stratification in Children's Sport Participation
}

\author{
Min Liu ${ }^{1}$, Rui Gao ${ }^{1}$, Klaudia Kukurová ${ }^{2, *}$, Walter $\mathbf{H o}^{2}$, Jian Wang ${ }^{3}$ \\ ${ }^{1}$ School of Physical Education and Educational Science, Tianjin University of Sport, Tianjin 301617, China \\ ${ }^{2}$ Faculty of Education, University of Macao, Macao, 999078, China \\ ${ }^{3}$ College of Exercise and Health Sciences, Tianjin University of Sport, Tianjin 301617, China
}

Received November 29, 2020; Revised February 23, 2021; Accepted March 12, 2021

\section{Cite This Paper in the following Citation Styles}

(a): [1] Min Liu, Rui Gao, Klaudia Kukurová, Walter Ho, Jian Wang, "A Review of Parental Input, Investment and Social Stratification in Children's Sport Participation," International Journal of Human Movement and Sports Sciences, Vol. 9, No. 2, pp. 265 - 274, 2021. DOI: 10.13189/saj.2021.090215.

(b): Min Liu, Rui Gao, Klaudia Kukurová, Walter Ho, Jian Wang (2021). A Review of Parental Input, Investment and Social Stratification in Children's Sport Participation. International Journal of Human Movement and Sports Sciences, 9(2), 265 - 274. DOI: 10.13189/saj.2021.090215.

Copyright $\bigcirc 2021$ by authors, all rights reserved. Authors agree that this article remains permanently open access under the terms of the Creative Commons Attribution License 4.0 International License

\begin{abstract}
Background: The difference of parental involvement in children's sport activities is a hot social issue when parental socio-economic background is investigated. Parental input, investment and social stratification could influence children's sport participation. Purpose: This study investigates the levels of parental physical activity and their investment in children's sport involvement across different socio-economic backgrounds. It expects to find out the best predictor in understanding the relationship of parental sport involvement across different socio-economic situation. Methods: Questionnaire survey method was selected and 863 valid questionnaires were collected. The questionnaire content included questions about families' basic information, social stratification, parental physical activity and parental investment in children's sport involvement. Results: When parents in low, middle and high social classes were compared, there were significant differences in parents' levels of physical activity, spiritual support, financial support, opportunities given and daily physical activity (all $\mathrm{p}<0.01$ ). Significant correlations between daily physical activity, physical exercise and social stratification were found $(p<0.01)$. Another significant correlation was found between spiritual and financial support, opportunities given and social stratification ( $\mathrm{p}<0.01$ ). Parental investment, parents' level of physical activity and physical exercise were the predictive values for understanding children's sport involvement. Conclusion: The higher social stratification, the higher parental physical activity and parental
\end{abstract}

investment will be involved in children's sport. Physical exercise had the highest predictive power as it related to parental investment in children's sports participation.

Keywords Social Stratification, Physical Activity, Physical Exercise, Investment in Children's Sports Involvement, Parental Socialization Model

\section{Introduction}

Parents are the first teachers of their children. Some of the determinants in developing children's and adolescents' sport habits are the result of their family's endeavours [1-2]. Parents are recognized as contributors because of their efforts to motivate their children or give them chances to participate in sports [3]. A study by Gerbert, Marloes and Koen [4] indicates that parents who frequently participate in sports themselves are more likely to promote similar sporting behaviours in their children and that such influence will accompany their children throughout their lives. An investigation research of Rodrigues, Padez and Machado-Rodrigues [5] showed that high degree of parental activity was significantly associated with sport participation frequency of children. In fact, the body of research on parental influence on the development of children's levels of physical activity is substantial. For example, Thompson et al. [6] focused on 
studying parental involvement in the physical activities of their children. Parents' involvement had an impact on the physical activity levels of their children. A large sample survey study from Amornsriwatanakul, Lester and Bull [7] revealed that parental support at the interpersonal level and sport equipment were two main factors in adolescent's preference towards physical activity. Similar results were also determined that parents' verbal encouragement motivated their children to participate in physical activities [8]. Parental support and interaction with children seem to be important factors for children's development of habits of regular physical activity behaviours [9-12] and it is interesting to see that such influences are closely related to the social and economic background of the parents [13-15].

Since the early 1990's, discussions have been emerging that focus on the theoretical frameworks of socialization in order to explain how and to what extent parents could influence the sporting behaviours of children. A theory presented by Eccles, Wigfield and Schiefele [16] as well as Fredricks and Eccles [17] focused on parental socialization, which suggested that the development of children's sporting behaviours can be the result of parents' attitudes and family practices towards children. Parents' sporting behaviours are imitated by their children, and parents' understanding of the development of an active lifestyle could affect the development of children's attitudes towards sports. Another popular concept comes from the study of socio-economic status (SES) [18]. SES focuses on the connection between children's physical activity levels and parents' educational background, income and socio-economic condition [19-21]. The study from Hoekman, Breedveld and Kraaykamp [22] reconfirmed the importance of family education level and household income for sports participation. Studies indicated that children who are in the low SES group will have higher chances of developing higher BMI and lower levels of physical activity and engage in more sedentary activities than children who are in the high SES group. This understanding is supported by studies such as physical activity and sedentary time on parents and children [23], parental influences on adolescents' physical activity and sedentary behaviour [24] and the effects of socioeconomic status and physical activity on adolescents [25]. Clark et al. [26] conducted the semi-structured interviews and found that low-income family faced different obstacles which could inhibit sport engagement of children.

These messages help to portray the importance of having parental support and the effects of SES on the behavioural development of children in sports and physical activities. This study follows the above understandings and presents a design for research on the financial input and investment from parents in different socio-economic groups for their children's participation in sports. This study combines the concepts of social stratification, parents' levels of physical activity and parental investment in children's sport involvement as the main variables. Family social stratification is regarded as an inevitable outcome of social and economic development. Within this context of analysis, the main feature of the study includes parental educational levels, parental employment status and household income [27]. Physical activity refers to any activity that consumes energy. Regarding the different forms of activities, physical activities include daily physical activity, such as work, transportation, housework and other activities requiring physical expenditure, and physical exercise, such as ball games, swimming and other sports events [28]. Parental investment in their children's sport involvement refers to the indirect ways in which parents influence their children's sports behaviours and mainly includes financial support, playing with their children, the extent of their encouragement and spiritual support as well as the provision of opportunities and experiences [29].

This study was conducted in Tianjin, a city of approximately 15 million people in China [30]. There are several reasons for selecting this city. According to a recent investigation, Tianjin has the highest number of overweight and obese children when compared with to the city of Beijing and Hebei Region [31]. Three schools in Tianjin were invited to participate in this study. These schools are in the districts of Binhai New Area, Jinnan and Nankai. The purpose of this selection was to avoid the overconcentration of participating schools in the wealthy district or in districts with a major population of migrants from villages. Jiannan and Nankai ranked in the middle of the personal taxation returns, and Binhai New District has the highest personal taxation record [32]. This selection was expected to ensure the inclusion of a sizable number of parents from the wealthy class for our analysis as well as a substantial number of families in a lower social stratification. The families' educational background and accessibility to public facilities for sport and physical activities were also considered. Social stratification in China was adopted to assign the family hierarchy according to different socio-economic backgrounds [33]. With these circumstances of consideration, the analysis of questions for understanding the differences in parental physical activities and their investment in their children's sport involvement, the correlation between family social stratification, parental physical activity and their investment in their children's sport involvement, and the investigation of family social stratification and parental physical activity as predictors of their children's sport involvement will be more reliable and valid for determining parental influence on their children.

This study examined research's questions if there were significant differences in parental physical activity and parental investment in their children's sport involvement among different social stratifications; correlation among social stratification and type of parental physical activity and parental investment in their children's sport involvement; if social stratification and type of parental 
physical activity have significant predictive power for parental investment in their children's sport involvement.

\section{Materials and Methods}

\subsection{Participants}

A total of 970 parents of students in grades 4 and 5 in three primary schools in Tianjin (China) were asked to fill out questionnaires. Due to the number of subjects and their wide distribution range, we decided, after communicating with school principals and obtaining their permission, that the questionnaires should be distributed to students by head teachers, then taken home and completed by parents, and finally returned by the students. This method enabled the efficient distribution and collection of the questionnaires at the same time.

\subsection{Methods and Tools}

Questionnaire survey method was used in this study. The questionnaire involved section of informed consent, research purpose introduction and the ethical standards including signature if respondents agreed with research and subsequent data processing. All information provided used for research purposes only and the respondents' relevant data were destroyed upon completion of the study. If respondents agreed with participating and processing their data, then they selected the choice "yes" and continued to fill in the questionnaire. Therefore, this study doesn't involve any potential conflicts of interest and respondents' personal information won't be publicly disclosed. The data collection and processing procedure was approved by the Ethics committee in Tianjin University of Sport.

According to sociological principles of questionnaire writing and the characteristics of the respondents and in reference to the related researchers' questionnaires [34-37], the "Questionnaire on physical activity and investment in children's sport involvement of primary school students' parents according to familial social stratification" was designed and included instruction, basic information and sub-scales (familial social stratification, parental physical activity and parental investment in their children's sport involvement). The validity of the content was examined by 4 related experts in the field and met the requirements. According to a reliability analysis, Cronbach's alpha values were 0.79 (social stratification), 0.73 (parents' physical activity) and 0.84 (parental investment in their children's sport involvement), and all met the reliability criteria.

A total of 970 questionnaires were distributed, and 945 questionnaires were returned, with a recovery rate of $97.4 \%$. After eliminating 82 questionnaires due to omissions, inattention and incompletion of questionnaires by parents, the remaining 863 questionnaires met the study criteria, and the effective recovery rate was $90.0 \%$.

\subsection{Mathematical Statistics Method}

Microsoft Office 2007 and SPSS 20.0 were used for statistical analysis. All data were determined to be normally distributed. Descriptive statistics were performed for all parameters, and the data are described as the means and standard deviations $(\mathrm{m} \pm \mathrm{s})$. Frequency and Descriptive Statistics, One-way Analysis of Variance (ANOVA) and Multiple linear regression were adopted, with a significant level of $\mathrm{p}=0.05$ and a very significant level $\mathrm{p}=0.01$.

(1) Frequency and Descriptive statistics were used to characterize the proportion of families, purpose of parental sports participation and factors that discourage their participation in sport. (2) The differences of parental physical activity and parental sport investment in their children's sport involvement among different social stratifications were evaluated by One-way ANOVA. (3) The association of parental sport investment in children's sport involvement with family social stratification and parental physical activity was assessed using the method of Multiple Linear Regression. In view of the combination of factors to sport investment in children's sport involvement, the Stepwise Multivariable Linear Regression Models were selected to make the significance of F-value of the whole regression models as small as possible. Pooled estimates from these factors were used to report effective estimation and their 95\% confidence intervals (CIs). Coefficient of Determination $\left(\mathrm{R}^{2}\right)$ was used to report the predictive power on parental sport investment. Correlation relationship between sport investment in children's sport involvement with family social stratification and physical activity was assessed by Pearson correlation coefficient which was the precondition to carry out regression analysis.

\section{Results}

The proportion of families in the middle social stratification (MSS) was the largest (54.3\%), followed by families in the low social stratification (LSS) (30.7\%) and high social stratification (HSS) (25.0\%). The purpose behind parental sports participation and factors that discourage their sports participation were also investigated (Fig 1). The main purpose of sports participation was diseases prevention (2.89 \pm 1.63$)$, followed by entertainment $(2.62 \pm 1.54)$, weight loss (2.44 \pm 1.54$)$, peer invitation (1.79 \pm 1.23$)$, sports skills improvement $(1.75 \pm 1.13)$ and social contact $(1.65 \pm 1.08)$; The main factors discouraging sports participation were no time $(2.73 \pm 1.72)$, followed by laziness $(2.13 \pm 1.44)$, no field $(1.93 \pm 1.87)$, no guidance $(1.74 \pm 1.20)$, no interest $(1.60$ $\pm 1.07)$, no company (1.54 \pm 1.07$)$, financial restrictions (1.48 \pm 0.99$)$, weak body (1.42 \pm 0.9$)$, fear of injury (1.37 
$\pm 0.84)$, no need $(1.31 \pm 0.78)$ and fear of ridicule $(1.24 \pm$ $0.72)$.
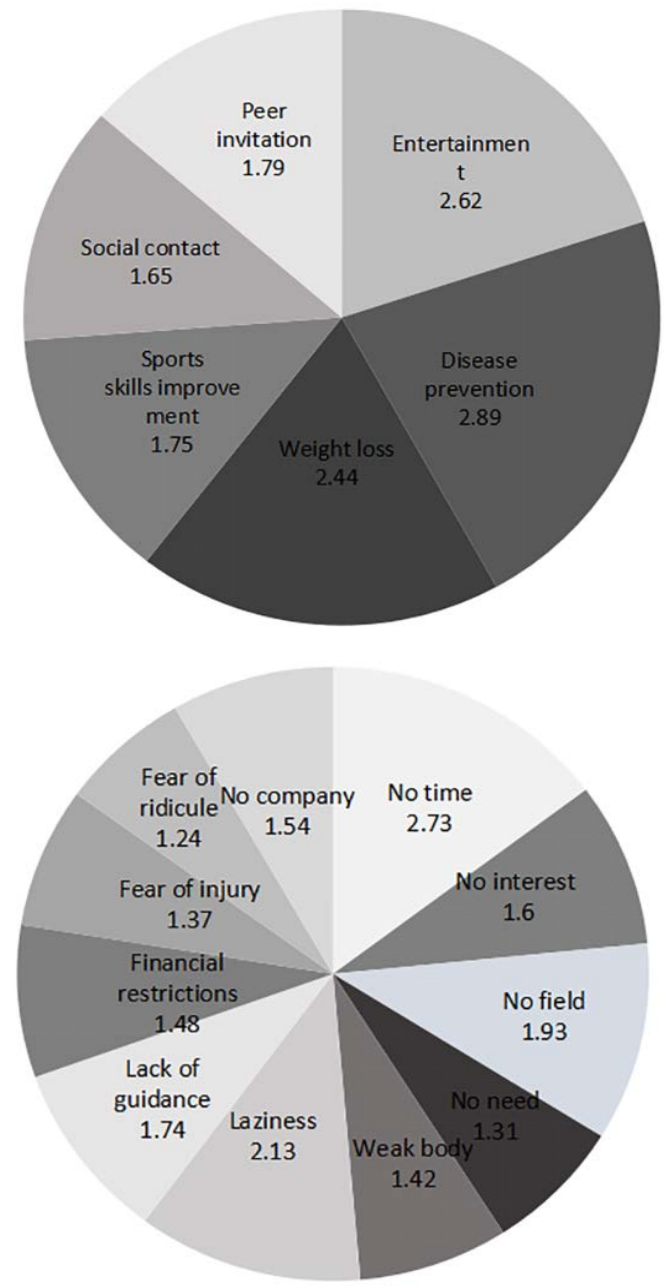

Figure 1. Purpose of parental sports participation and reasons to discourage parents from participating in sports

This study examined the differences of parental physical activity and parental investment in their children's sport involvement in different social stratifications. Table 1 shows the average means and standard deviations of parents' physical activity (daily physical activity and physical exercise) and investment in their children's sport involvement (spiritual support, accompanied time, financial support, given opportunities) among social stratification and the significance between them.
By using ANOVA, it was determined that the "overall level" of physical activity between parents in different family social classes was significant $(F(2,860)=7.26$, $p$ $<0.01$ ). After a post hoc analysis, the physical activity levels of parents in HSS (18.79 \pm 2.97$)$ were significantly higher than those of parents in LSS $(17.66 \pm 2.37)$ and MSS (18.04 \pm 2.91$)$. At certain "point levels", it was determined that there were significant differences in daily physical activity $(\mathrm{F}(2,860)=12.81, \mathrm{p}<0.01)$ and physical exercise $(\mathrm{F}(2,860)=27.34, \mathrm{p}<0.01)$ among parents from different social classes. After the post hoc analysis, the physical exercise levels of parents in HSS $(19.19 \pm 5.28)$ were significantly higher than those of parents in MSS $(17.20 \pm 4.84)$ and LSS (15.55 \pm 4.03$)$. A significant difference also existed between parents in MSS $(17.20 \pm 4.84)$ and LSS $(15.55 \pm 4.03)$, favouring parents from MSS. Vice versa, the daily physical activity levels of parents in the LSS $(19.77 \pm 2.92)$ was significantly higher than level of parents in MSS (18.88 \pm 2.88$)$ and HSS $(18.40 \pm 2.52)$.

The "overall level" of investment in children's sport involvement between parents among different family social classes (Table 1$)$ was significant $(F(2,860)=15.90$, $\mathrm{p}<0.01$ ). After using the post hoc analysis, the investment in children's sport involvement of parents in HSS (18.63 \pm 3.14$)$ was significantly higher than the level of parents in LSS $(16.71 \pm 3.12)$ and MSS (16.71 \pm 3.12$)$ and was significantly higher in those parents in MSS (16.71 \pm 3.12 ) compared to parents in LSS (16.71 \pm 3.12$)$. At the "point levels" (spiritual support, accompanied time, financial support and given opportunities), significant differences were found in spiritual support ( $\mathrm{F}(2,860=$ 11.49, $\mathrm{p}<0.01)$, financial support $(\mathrm{F}(2,860)=24.11, \mathrm{p}<$ $0.01)$ and given opportunities $(\mathrm{F}(2,860)=8.60, \mathrm{p}<0.01)$, but there was no significant difference in accompanied time $(\mathrm{F}(2,860)=0.55, \mathrm{p}>0.05)$. After a post hoc analysis, the spiritual support, financial support and given opportunities of the parents in HSS (21.18 $\pm 4.24,16.81 \pm$ $5.16,21.18 \pm 4.24)$ were significantly higher than those of the parents in LSS $(19.17 \pm 4.57,13.20 \pm 4.47,19.17 \pm$ 4.57) and MSS (19.89 \pm 4.54, $14.96 \pm$ 5.22, $19.89 \pm 4.54)$. Additionally, significant differences were found between parents in MSS (19.89 \pm 4.54, $14.96 \pm 5.22)$ and LSS $(19.17 \pm 4.57,13.20 \pm 4.47)$ regarding spiritual and financial support, favouring parents from MSS. 
Table 1. Physical activity and sports investment of primary school students' parents in different social stratifications

\begin{tabular}{|c|c|c|c|c|c|c|}
\hline Group & $\begin{array}{c}\text { LSS }^{1} \\
\mathrm{~N}=265(\mathrm{~m} \pm s)\end{array}$ & $\begin{array}{c}\text { MSS }^{2} \\
\mathrm{~N}=469(\mathrm{~m} \pm s)\end{array}$ & $\begin{array}{c}\mathrm{HSS}^{3} \\
\mathrm{~N}=129(\mathrm{~m} \pm s)\end{array}$ & $\mathrm{F}$ & P & Post-hoc \\
\hline Daily Physical Activity & $19.77 \pm 2.92$ & $18.88 \pm 2.88$ & $18.40 \pm 2.52$ & 12.81 & $0.00^{* *}$ & $1>2,3$ \\
\hline Physical Exercise & $15.55 \pm 4.03$ & $17.20 \pm 4.84$ & $19.19 \pm 5.28$ & 27.34 & $0.00^{* *}$ & $3>2,1 ; 2>1$ \\
\hline Physical Activity (overall) & $17.66 \pm 2.37$ & $18.04 \pm 2.91$ & $18.79 \pm 2.97$ & 7.26 & $0.00^{* *}$ & $3>2,1$ \\
\hline Spiritual support & $19.17 \pm 4.57$ & $19.89 \pm 4.54$ & $21.18 \pm 4.24$ & 11.49 & $0.00^{* *}$ & $3>2,1 ; 2>1$ \\
\hline Accompanied time & $15.22 \pm 4.79$ & $15.47 \pm 4.81$ & $15.74 \pm 4.89$ & 0.55 & 0.58 & \\
\hline Financial support & $13.20 \pm 4.47$ & $14.96 \pm 5.22$ & $16.81 \pm 5.16$ & 24.11 & $0.00^{* *}$ & $3>2,1 ; 2>1$ \\
\hline Given opportunity & $19.17 \pm 4.57$ & $19.89 \pm 4.54$ & $21.18 \pm 4.24$ & 8.60 & $0.00^{* *}$ & $3>2,1$ \\
\hline Sports investment (overall) & $16.71 \pm 3.12$ & $17.54 \pm 3.30$ & $18.63 \pm 3.14$ & 15.90 & $0.00^{* *}$ & $3>2,1 ; 2>1$ \\
\hline
\end{tabular}

1-Low Family Social Stratification; 2-Middle Family Social Stratification; 3-High Family Social Stratification;

** statistically highly significant as $\mathrm{P}<0.01$

Table 2. Pearson correlation between sport investment in children's sport involvement with family social stratification and physical activity

\begin{tabular}{|c|c|c|c|c|c|c|c|c|}
\hline & $\begin{array}{c}\text { PA } \\
\text { (overall) }\end{array}$ & Daily PA & PE & $\begin{array}{c}\text { Sports investment } \\
\text { (overall) }\end{array}$ & $\begin{array}{c}\text { Spiritual } \\
\text { support }\end{array}$ & Accompanied time & $\begin{array}{c}\text { Financial } \\
\text { support }\end{array}$ & Given opportunity \\
\hline FSS $^{1}$ & $0.11^{* *}$ & $-0.22^{* *}$ & $0.25^{* *}$ & $0.22^{* *}$ & $0.20^{* *}$ & 0.05 & $0.25^{* *}$ & $0.17^{* *}$ \\
\hline Daily PA & \multicolumn{2}{|c}{} & 0.05 & $0.08^{* *}$ & $0.09^{* *}$ & -0.01 & 0.01 \\
\cline { 1 - 7 } PE $^{3}$ & & & $0.44^{* *}$ & $0.22^{* *}$ & $0.39^{* *}$ & $0.39^{* *}$ & $0.28^{* *}$ \\
\hline
\end{tabular}

${ }^{1}$ FSS - Family Social Stratification; ${ }^{2} \mathrm{PA}$ - physical activity; ${ }^{3} \mathrm{PE}$ - physical exercise;

** statistically highly significant as $\mathrm{P}<0.01$

Table 2 shows a Pearson correlation between observed variances of the study. By Pearson correlation analysis, the correlation between family social stratification and the "overall level" of parental physical activity was positive and significant, albeit low $(r=0.11 ; p<0.01)$. At the "point levels", the correlation coefficients between daily physical activity and physical exercise with family social stratification were -0.22 and $0.25(\mathrm{p}<0.01)$, respectively, but the correlations were both low.

The correlation coefficient between family social stratification and "overall level" of investment in children's sport involvement by primary school students' parents was positive and low but significant $(\mathrm{r}=0.22$; $\mathrm{p}<$ 0.01 ). At the "point levels" of parental investment in their children's sport involvement spiritual support, financial support, given opportunities and family social stratification the correlation coefficients were $0.20,0.25$ and $0.17(\mathrm{p}<0.01)$, respectively; the correlations were positive and significant, but all were low. However, the correlation coefficient between accompanied time and family social stratification was not statistically significant $(r=0.05 ; p>0.05)$.

There were no significant correlations between daily physical activity and financial support, given opportunities and sports investment (overall), respectively $(r=-0.01,0.01$ and $0.05 ; \mathrm{p}>0.05)$. However, the correlation coefficients between daily physical activity of parents and spiritual support and accompanied time were 0.08 and $0.09(\mathrm{p}<0.05)$. Additionally, the correlation coefficients between physical exercise and spiritual support, accompanied time, financial support, given opportunities and sports investment (overall) were 0.22 , $0.39,0.39,0.28$, and 0.44 , respectively $(\mathrm{p}<0.01)$. All of the significant correlations were positive but low.

The predictive power of family social stratification and parental physical activity on parental sport investment in children's involvement was analysed by multiple linear regression. The multivariate correlation coefficient (r) was 0.46 , and $R^{2}=0.21$, indicating that the family's social stratification level, physical exercise and daily physical exercise could predict the variance of overall parental investment in children's involvement in sports by $21 \%$.

(1) The standardized regression equation for overall parental investment in their children's sport involvement $=10.11+0.41 \times$ physical exercise + $0.14 \times$ family social stratification score $+0.09 \times$ daily physical activity; $\mathrm{r}=0.46$ and $\mathrm{R}^{2}=0.21 ; \mathrm{F}=$ 78.06, $\mathrm{SE}=2.91$.

(2) The standardized regression equation for spiritual support $=5.09+0.17 \times$ physical exercise $+0.18 \times$ family social stratification score $+0.22 \times$ daily physical activity; $\mathrm{r}=0.29$ and $\mathrm{R}^{2}=0.08 ; \mathrm{F}=25.56$, $\mathrm{SE}=2.94$.

(3) The standardized regression equation for time spent by parents accompanying their children $=12.38+$ $0.39 \times$ physical exercise $+0.09 \times$ daily physical activity, $\mathrm{r}=0.40$ and $\mathrm{R}^{2}=0.16 ; \mathrm{F}=80.48, \mathrm{SE}=$ 4.42.

(4) The standardized regression equation for financial support $=10.74+0.34 \times$ physical exercise $+0.16 \times$ family social stratification score, $\mathrm{r}=0.41$ and $\mathrm{R}^{2}=$ $0.17 ; \mathrm{F}=89.44, \mathrm{SE}=4.67$. 
(5) The standardized regression equation for parents giving opportunities to their children $=10.74+0.26$ $\times$ physical exercise $+0.10 \times$ family social stratification score, $\mathrm{r}=0.30$ and $\mathrm{R}^{2}=0.09 ; \mathrm{F}=42.58$, $\mathrm{SE}=4.34$.

According to the results from regression analysis, 21\% of the variance in parental overall investment in their children's sport involvement was predictable from family social stratification and parental physical activity. The highest predictor was physical exercise, followed by $8 \%$, $16 \%, 17 \%$ and $9 \%$, respectively, of variance in spiritual support, accompanied time, financial support and given opportunities, all of which were predicted from physical exercise, daily physical activity and family social stratification scores. Physical exercise was the most important factor. Family social stratification and parental physical activity were significant predictors of parental investment $(\mathrm{p}<0.05)$.

\section{Discussions}

Although many countries actively promote citizens' participation in physical activity in various degree, many studies found that social differentiation of participation in physical activity exists due to difference of religion background, policies and economic development in different countries [38-40]. Researchers focusing on the influence factors of sports participation from different countries obtained various conclusions and a large number of studies have showed that family influence [41], socio-economic background [42], capital support [43] and income are the important factors among the sports participation and have close relationship with sports behavior. Ruseski and Maresova [44] conducted an international comparative analysis of physical activity participation data from 34 countries/regions and also found that income, education level, hours worked were closely related to physical exercise participation. In other words, parental income, employment and educational background appear to have a strong impact on physical activities that are available to children. The observation of this social stratification concept and its relationship to sports behaviour is supported in this study. A positive correlation between physical exercise and family income is found in the study. The results of this study show that parents from a higher social stratification are more active, partake in physical exercise at sports clubs or gymnasiums, or participate in different sport courses more than parents from MSS and LSS; in addition, parents from a lower social stratification had higher scores of daily physical activities. Similar results have also been reported in a study by Brophy et al. [45]. Bouchard, Blair and Haskell [46] also discovered similar observations that parents with higher social and economic status participate in household physical activities less than parents from lower social and economic status.

Family income seems to be a contributing factor affecting the amount of time that a family is able to participate in physical activities [47]. Mutz and Albrecht [48] also found that children from families with lower incomes (less than 2000 euro per month) were more likely to have 63 minutes of sports-related physical activities per day than children from families with higher (4000 euro per month) incomes, which may reach up to 85 minutes of activities per day. Children from families with lower social classes were also less likely to be involved in sports activities than children from families with lower social classes [49]. Parents from HSS and MSS have higher incomes and are able to spend more money on activities in gymnasiums or various sports courses. When income serves as a factor, families from the lower income group will have their physical activities restricted to housework or activities that are supported by public funding.

Another purpose of this study is to observe the influence of a family's social stratification, parent's physical activity and parent's investment on their children's sports involvement. As observed in this study, there are significant differences in spiritual support, financial support and opportunities for participating in sports activities for children between the parents from different socioeconomic backgrounds. Nevertheless, there is no significant difference in the amount of time spent accompanying their children to sports activities from the parents of different socioeconomic backgrounds. Parents devoted almost equal amounts of time to their children when partaking in sports exercises. In other words, even if parents from LSS don't have extra money to afford those sports or physical activities requiring payment, they are willing to spend time to accompany with their children to do some free physical activities. Siekańska [50] observed that parental involvement was correlated with their child's level of sports achievements. In other words, parents' time spent on sports increases when their children have a high level of sports achievement. Nevertheless, this finding was not observed in this study. Rather, this study focused on the spiritual support, financial support, available opportunities and involvement in children's physical exercises between families from different socioeconomic backgrounds, and a significant and positive correlation was observed in these areas of concern with physical exercises. Weaker relationships and correlations were observed in daily physical activity and spiritual support, financial support, accompanied time and available opportunities. By using regression analysis, the observation is supported that parental physical exercise is the strongest predictor of variance in spiritual support, financial support, accompanied time and available opportunities. Financial support and given opportunities are related to a family's social class.

If a family belongs to a higher social class, there is greater financial support and more opportunities available 
to their children. This observation was supported and could be explained, for example, by membership recruitment in different sports clubs or sports courses. Jekauc, Reimers, Wagner and Woll [51] found that adolescents from a higher socioeconomic class have three times more opportunities to become members of some sports clubs (with parental permission) than children from lower socioeconomic classes and that socioeconomic status was a significant predictor of membership in sports clubs. Organized sports activities by sports clubs and self-organized sports activities have developmental benefits, and a recent study indicated the importance of children's growth when they are involved in both of these types of activities [49]. Families from a higher social class are able to provide greater financial support for their children to become involved in sports. This observation indicates higher chances for available opportunities when compared with children from families of lower social class. Thompson et al. [6] interviewed parents of 10- to 11-year-old schoolchildren in Bristol, UK, and found that families of higher socioeconomic status could be given better transportation and financial support for children to attend activities in sports clubs than children from lower socioeconomic backgrounds. Nevertheless, higher verbal encouragement was observed in children from lower family income groups in activities that took place on the street or at public facilities. Parents from a lower family social class may relate to this situation, especially those low-income families who have no extra capital to provide their children with the financial support needed to pay membership fees, purchase sports equipment or participate in sports club activities that require extensive travelling. In an investigation of 8 child athletes and their parents, Wheeler [52] found that sports culture could indeed be spread throughout a family when there are high levels of investment in areas such as financial support, encouragement, teaching and rewards, etc. In turn, positive family sports culture atmosphere could positively improve children's sport participation during their teenage years [53]. Therefore, investigating the sports behaviour of parents and their investment in their children's sports involvement may serve as important predictors and provide a necessary understanding of the development of children's regular behaviour in sports and physical activities.

In addition to this study and through a regression analysis, parental participation in physical exercise was the strongest predictor of variance in spiritual support, financial support, accompanied time and available opportunities. This finding coincides with a previous observation by Mutz and Albrecht [48] that children who are active in sports have families who devote more time to physical exercise than children from families whose parents engage in less than 30 minutes of daily physical exercise. A previous study by Gerbert et al. [4] indicated that parents who frequently participate in sports themselves are more likely to improve similar sporting behaviours in their children and that such an influence will accompany their children throughout their lives. Brophy et al. [45] found that parents who had better health behaviours and were willing to spend more time playing with their children were able to influence their children to achieve higher levels of physical activity. Anderson and Hughes [54] found that parents who value household chores had unexpected negative effects on children, such as more TV viewing, thus having a negative impact on encouraging children to participate in team sports. Therefore, if parents are fond of doing some physical exercise, they are more involved in encouraging and supporting in children sport participation, mainly including spiritual support, accompanied time, financial support and given opportunities.

This study provides clear evidence that parental physical exercise is the strongest predictor in understanding children's sports involvement. The family's socioeconomic conditions, parents' sports behaviour and parental investment in their children's sports participation are three important components and predictable elements in understanding children's development of sports behaviour. Therefore, from the Pearson correlation and regression results of this study, we may conclusively demonstrate a significant correlation between physical activity and parental investment in children's sports involvement. We also find that the most predictive powers in children's sports involvement, which would have an important underlying meaning in the research field of parental and children's physical activities.

\section{Conclusions}

There were significant differences in the physical activities and investment in children's sport involvement between parents from different family social classes. Parental physical activities and investment can be obviously affected by social and economic conditions. Parental physical activity and investment in children's sport involvement were significantly higher in HSS than in LSS and MSS. In a word, there was a positive relationship between family social hierarchy and parents' involvement in physical activities and their children's sports, respectively. Additionally, there was a positive association between the physical activity levels of parents and parental involvement in their children's sports. The government should therefore increase its investment in mass sports programmes, and especially increase the investment support in the construction of sports infrastructure in less developed areas where the majority of inhabitants have low and middle household incomes. At the same time, the government should promote sports and guide the population in understanding the physical benefits of sports. Policies supportive of sports and 
appropriate financial support should be implemented for children living in poor family conditions.

There was a significant correlation between the physical activity levels and sport involvement of parents and their children's sport involvement. Children's sport participation is able to be influenced by parental investment. Primary school students' parents bear the burden of the dual mission of exercising themselves and investing in their children's participation in sports; in other words, parents are responsible for both adhering to good personal physical exercise habits and guiding and supporting the participation of their children in healthy sports. Family social stratification and levels of parental physical activity had significant predictive power for overall parental investment in their children's sport involvement and "physical exercise" had the highest predictive power. Physical activity plays an important role in family behavior. Companies and other relevant organizations should pay attention to promoting sports culture and to the health of their staff and workers and, at the same time, provide employees with appropriate sports opportunities. Public welfare organizations and others with suitable resources should provide children from lower social classes with sport opportunities and offer financial assistance to the best of their ability by providing sports clothing, equipment and funding, etc. Parents could then offer enough opportunities for sport and physical activities in their children's daily lives.

Due to the limitations of the research conditions, this study only took the form of a questionnaire survey and did not use comprehensive investigation methods such as interviews to conduct in-depth research on the relationship between parents' and children's participation in sports. However, based on the results of this study, it can be seen that family social stratification and levels of parental physical activity do have predictive power for determining parental investment in their children's sport involvement, and this provides theoretical support for future studies on sports at the family level.

\section{Acknowledgements}

The authors would like to thank all respondents, children, their parents, and teachers. No source of funding was obtained for this study and the authors have no conflicts of interest to declare.

\section{REFERENCES}

[1] Birchwood, D., Roberts, K., Pollock, G. Explaining differences in sport participation rates among young adults: Evidence from the South Caucasus, European Physical Education Review, vol.14, no.3, pp. 283-298, 2008, DOI: 10.1177/1356336X08095667.
[2] Neil, L. O'., Amorosea, A. J. Autonomy support and control within mother-father parenting structures: A person-centered approach in youth sport, Psychology of Sport and Exercise, vol.53, 101854, 2021, DOI: 10.1016/j.psychsport.2020.101 854.

[3] Harenberg, S., Karreman, E., Riemer, H. A., Dorsch, K. D. Motivation for participation in sports: The influence of parents on their child, Journal of Exercise, Movement, and Sport (JEMS): a repository of SCAPPS refereed abstracts, vol.42, no.1, pp. 108, 2010.

[4] Gerbert, K., Marloes, O., Koen, B. Starting a sport in the Netherlands: A life-course analysis of the effects of individual, parental and partner characteristics, International Review for the Sociology of Sport, vol.48, no.2, pp. 153-170, 2012, DOI: $10.1177 / 1012690211432212$.

[5] Rodrigues, D., Padez, C., Machado-Rodrigues, A. M. Active parents, active children: The importance of parental organized physical activity in children's extracurricular sport participation, Journal of Child Health Care, vol.22, n.1, pp. 159-170, 2017, DOI: 10.1177/1367493517741686.

[6] Thompson, J. L., Jago, R., Brockman, J. R., Cartwright, K., Page, A. S., Fox, K. R. Physically active families de-bunking the myth? A qualitative study of family participation in physical activity, Child Care Health and Development, vol.36, no.2, pp. 265-274, 2010, DOI: 10.1111/j.1365-2214.2009.01051.x.

[7] Amornsriwatanakul, A., Lester, L., Bull, F. C., Rosenberg, M. Ecological correlates of sport and exercise participation among Thai adolescents: A hierarchical examination of across-sectional population survey, Journal of Sport and Health Science, pp. 1-14, 2020, DOI: 10.1016/j.jshs.2020.0 4.012 .

[8] Beets, M. W., Vogel, R., Chapman, S., Pitetti, K. H., Cardinal, B. J. Parent's social support for children's outdoor physical activity: do weekdays and weekends matter? Sex Role, vol.56, no.2, pp. 124-131, 2007, DOI: 10.1007/s11199-006-9154-4.

[9] Panter, J. R., Jones, A. P., van Sluijs, E. M., Griffin, S. J. Attitudes, social support and environmental perceptions as predictors of active commuting behaviour in school children, Journal of Epidemiology and Community Health, vol.64, no.1, 41-48, 2010, 2010, DOI: 10.1136/jech.2009.086918.

[10] Trost, S. G., Sallis, J. F., Pate, R. R., Freedson, P. S., Taylor, W. C., Dowda, M. Evaluating a model of parental influence on youth physical activity, American Journal of Preventive Medicine, vol.25, no,4, pp. 277-82, 2003, DOI: 10.1016/s0749-3797(03)00217-4.

[11] Karmali, S., Battram, D.S., Burke, S.M., Cramp, A., Johnson, A.M., Mantler, T., Morrow, D., Ng, V., Pearson, E.S., Petrella, R.J., Tucker, P., Irwin, J.D. Perspectives and impact of a parent-child intervention on dietary intake and physical activity behaviours, parental motivation, and parental body composition: A randomized controlled trial, International Journal of Environmental Research and Public Health, vol.17, n.18, pp. 6822, 2020, DOI: 10.3390/ijerph17186822.

[12] Park, J. W., Hwang, J., Lee, C.G., Ahn, H., Kim, H. The impact of parental incarceration on sport participation trajectories from adolescence to young adulthood. International Journal of Environmental Research and Public Health, vol.17, n.14, pp. 5229, 2020, DOI: 


\subsection{0/ijerph17145229.}

[13] Dollman, J., Lewis, N. R. The impact of socioeconomic position on sport participation among South Australian youth, Journal of Science and Medicine in Sport, vol.13, no.3, pp. 318-322, 2010, DOI: 10.1016/j.jsams.2009.04.007.

[14] Marcen, C., Gimeno, F., Gómez-Bahillo, C., Sáenz, A. Socioeconomic status, parental support, motivation and self-confidence in youth competitive sport, Procedia - Social and Behavioural Sciences, vol.82, pp. 750-754, 2013, DOI: 10.1016/j.sbspro.2013.06.342.

[15] Nielsen, G., Grønfeldt, V., Toftegaard, J., Andersen, L. B. Predisposed to participate? The influence of family socio-economic background on children's sports participation and daily amount of physical activity, Sport in Society, vol.15, no.1, pp. 1-27, 2012, DOI: 10.1080/03031853.2011.625271.

[16] Eccles, J. S., Wigfield, A., Schiefele, U. Motivation to succeed. In: Damon, W. and Eisenberg, N., Eds., Handbook of Child Psychology: Social, Emotional, and Personality Development, John Wiley \& Sons Inc., Hoboken, NJ, US, pp. 1017-1095, 1998.

[17] Fredricks, J. A., Eccles, J. S. Family socialization, gender, and sport motivation and involvement, Journal of Sport and Exercise Psychology, vol.27, no.1, pp. 3-31, 2005, DOI: 10.1123/jsep.27.1.3.

[18] Huurre, T., Aro, H., Rahkonen, O. Well-being and health behaviour by parental socioeconomic status. A follow-up study of adolescents aged 16 until 32 years of age, Social Psychiatry and Psychiatric Epidemiol, vol.38, no.5, pp. 249-255, 2003, DOI: 10.1007/s00127-003-0630-7.

[19] Drenowatz, C., Eisenmann, J. C., Pfeiffer, K. A., Welk, G., Heelan, K., Gentile, D., Walsh, D. Influence of socio-economic status on habitual physical activity and sedentary behaviour in 8 to 11 year old children, BMC Public Health, vol.10, pp. 214, 2010, DOI: 10.1186/1471-2458-10-214.

[20] Gorely, T., Marshall, S. J., Biddle, S. J. H. Couch kids: correlates of television viewing among youth, International Journal of Behavioral Medicine, vol.11, pp. 152-163, 2004, DOI: 10.1207/s15327558ijbm1103_4.

[21] Sallis, J. F., Zakarian, J. M., Hovell, M. F., Hofstetter, C.R. Ethnic, socioeconomic, and sex differences in physical activity among adolescents, Journal of Clinical Epidemiology, vol.49, no.2, pp. 125-134, 1996, DOI: 10.1016/0895-4356(95)00514-5.

[22] Hoekman, R., Breedveld, K., Kraaykamp, G. Sport participation and the social and physical environment: explaining differences between urban and rural areas in the Netherlands, Leisure Studies, vol.36, n.3, pp. 357-370, 2017, DOI: $10.1080 / 02614367.2016 .1182201$.

[23] Jago, H., Fox, K. R., Page, A. S., Brockman, R., Thompson, J. L. Parent and child physical activity and sedentary time: do active parents foster active children? BMC Public Health, vol.10, pp. 194, 2010, DOI: 10.1186/1471-2458-10-194.

[24] Bauer, K. W., Nelson, M. C., Boutelle, K. N., Neumark-Sztainer, D. Parental influences on adolescents' physical activity and sedentary behavior: longitudinal findings from Project EAT-II, International Journal of
Behavioral Nutrition and Physical Activity, vol.5, no.1, pp. 12-18, 2008, DOI:10.1186/1479-5868-5-12.

[25] Stalsberg, R., Petersen, A. V. Effects of socioeconomic status on the physical activity in adolescents: a systematic review of the evidence, Scandinavian Journal of Medicine \& Science in Sports, vol.20, no.3, pp. 368-383, 2010, DOI: 10.1111/j.1600-0838.2009.01047.x.

[26] Clark, M., Costas-Bradstreet, C., Holt, N. L., Spence, J. C. Parental perceptions of a national program that funds sport participation for low-income children and youth in Canada, Leisure Sciences, 2019, DOI: 10.1080/01490400.2019.1700 573.

[27] Wijtzes, A. I., Jansen, W., Bouthoorn, S. H., Pot, N., Hofmam, A., Jaddoe, V. W. V., Raat, H. Social inequalities in young children's sports participation and outdoor play, International Journal of Behavioural Nutrition and Physical Activity, vol.11, no.1, pp. 155-164, 2014, DOI:10.1186/s12 966-014-0155-3.

[28] Heyward, V. H. Advanced Fitness Assessment and Exercise Prescription (6th ed), Champaign, Illinois: Human Kinetics, 2010.

[29] Bois, J. E., Lalanne, J., Delforge, C. The influence of parenting practices and parental presence on children's and adolescents' pre-competitive anxiety, Journal of Sports Sciences, vol.27, no.10, pp. 995-1005, 2009, DOI: 10.1080/02640410903062001.

[30] World Population Review. Tianjin population, Online available from http://worldpopulationreview.com/world-citi es/tianjin-population/.

[31] Hong, H. X. Investigation and comparative study on the physical condition of students in Beijing - Tianjin - Hebei region, Journal of Jilin Sport University, vol.34, no.3, pp. 331-35, 2018, DOI:10.13720/j.cnki.22-1286.2018.03.007.

[32] Tianjin Municipal Bureau of Statistics and Survey Office of the National Bureau of Statistics in Tianjin. Tianjin Statistic Yearbook. Beijing: China Statistics Press, 2016.

[33] Lu, X. Y. The research report of the contemporary Chinese social classes. Beijing: Social Sciences Academic Press, 2002.

[34] Guo, C. Y. Research on family socioeconomic status, peer relationships and academic achievement (Master's thesis). National Pingtung University of Education, Pingtung, 2006.

[35] Xia, J. X. The investigation of parental participation in physical exercise of primary and secondary school students in cities and towns in Shandong Province (Master's thesis). Beijing Sport University, Beijing, 2010.

[36] Lai, Y. X. Expectancy-value beliefs and behavioral involvement of parents, children's perceived quality of parents' involvement, children's expectancy-value beliefs, and sport participation (Master's thesis). National Taiwan College of Physical Education, Taichung, 2011.

[37] Tan, X. C. A Study On Influence Of Parents’ Education level And Occupational Status On Children's Participation Of Sports-A Case Study of Six Primary Schools in Shaoyang City (Master's thesis). Guangxi Normal University, Guilin, 2011. 
[38] Stempel, C. Sport as high culture in the USA, International Review for the Sociology of Sport, vol,55, n.8, pp. 1167-1191, 2020, DOI: 10.1177/1012690219870067.

[39] Müller-Schoell, T. The Diversity of National Sport Development Institutions, The International Journal of the History of Sport, vol.35, n.9, pp. 819-835, 2018, DOI: 10.1080/09523367.2018.1534831.

[40] Lefèvrea, B., Routiera, G., Llopis-Goigb, R. Sports participation in France and Spain: An international comparison of voraciousness for sport, Poetics, vol.81, 101429, 2020, DOI: 10.1016/j.poetic.2019.101429.

[41] Mackintosh, C., Dempsey, C. The British Asian Muslim male sport participation puzzle: an exploration of implications for sport development policy and practice, Journal of Youth Studies, vol.20, n.8, pp. 974-996, 2017 DOI: $10.1080 / 13676261.2017 .1281387$.

[42] Scheerder, J., Vos, S. Social stratification in adults' sports participation from a time-trend perspective results from a 40-year household study, European Journal for Sport and Society, vol.8, no.1-2, pp. 31-44, 2011, DOI: 10.1080/16138171.2011.11687868.

[43] Nałęcz, H., Skrok, Ł., Majcherek, D., Biernat, E. Through Sport to Innovation: Sustainable Socio-Economic Development in European Countries, Sustainability, vol.12, pp. 10489, 2020, DOI: 10.3390/su122410489.

[44] Ruseski, J. E., Maresova, K. Economic freedom, sport policy, and individual participation in Physical Activity: an international comparison, Contemporary Economic Policy, vol.32, n.1, pp. 42-55, 2014, DOI: 10.1111/coep.12027.

[45] Brophy, S., Cooksey, R., Lyons, R. A., Thomas, N. E., Rodgers, S. E., Gravenor, M. B. Parental factors associated with walking to school and participation in organised activities at age 5: analysis of the Millennium Cohort Study, BMC Public Health, vol.11, no.14, pp. 1-9, 2011, 2011, DOI: 10.1186/1471-2458-11-14

[46] Bouchard, C., Blair, S. N., Haskell, W. L. Physical activity and health (2nd ed). Champaign, Illinois: Human Kinetics,
2012.

[47] Hua, Q. C. How does family income dictate the labor force participation behavior of married women? (Master's thesis). Georgetown University, Washington, DC, 2014.

[48] Mutz, M., Albrecht, P. Parents' Social Status and Children's Daily Physical Activity: The Role of Familial Socialization and Support, Journal of Child and Family Studies, vol.26, no.11, pp. 3026-3035, 2017, DOI: 10.1007/s10826-017-080 8-3.

[49] Wiium, N., Säfvenbom, R. Participation in Organized Sports and Self-Organized Physical Activity: Associations with Developmental Factors, International Journal of Environmental Research and Public Health, vol.16, no.4, pp. 585-601, 2019, DOI: 10.3390/ijerph16040585.

[50] Siekańska, M. Athletes’ perception of parental support and its influence on sports accomplishments - a retrospective study, Human Movement, vol.13, no.4, pp. 380-387, 2012, 2012, DOI: 10.2478/v10038-012-0046-x.

[51] Jekauc, D., Reimers, A. K., Wagner, M. O., Woll, A. Physical activity in sports clubs of children and adolescents in Germany: results from a nationwide representative survey, Journal of Public Helath, vol.21, no.6, pp. 505-513, 2013, DOI: $10.1007 / \mathrm{s} 10389-013-0579-2$.

[52] Wheeler, S. The significance of family culture for sports participation, International Review for the Sociology of Sport, vol.47, no.2, pp. 235-252, 2012, DOI: $10.1177 / 1012690211403196$.

[53] Strandbu, Å., Bakken, A., Stefansen, K. The continued importance of family sport culture for sport participation during the teenage years, Sport, Education and Society, vol.25, n.8, pp. 931-945, 2020, DOI: 10.1080/13573322.20 19.1676221.

[54] Anderson, C. B., Hughes, S. O., Fuemmeler, B. F. Parent-child attitude congruence on type and intensity of physical activity: testing multiple mediators of sedentary behaviour in older children, Health Psychology, vol.28, no.4, pp. 428-438, 2009, DOI: 10.1037/a00145. 